\title{
La ciencia como garantía de la historia. José Ingenieros y su lectura de la novela de Sicardi
}

\section{Science as a guarantee of the story. José Ingenieros and reading the novel Sicardi}

\author{
María Carla Galfione ${ }^{1}$
}

\begin{abstract}
Resumen
Como tantos otros médicos argentinos de fines del siglo XIX, Francisco Sicardi escribe una serie de novelas, reunidas en Libro extraño (1902). La última novela de la serie lleva por título "Hacia la justicia" y suscita la crítica de José Ingenieros. Esa novela presenta un detallado cuadro de la sociedad porteña de entonces, con sus tipos más característicos, acordando con algunos de los principios del naturalismo. Ingenieros reconoce esas características, pero su crítica es lapidaria: apenas debe proponer una resolución para el conflicto político, el autor abandona la ciencia, traiciona los principios del naturalismo y confía el curso de la historia a la intervención de una ilusión. En nuestro trabajo analizamos la crítica de Ingenieros, intentando reconocer su sentido y alcance. Consideramos algunos aportes del naturalismo literario en su discurso, pero advertimos que la preocupación central de este autor radica en la postulación del vínculo entre ciencia e historia. La literatura se pone al servicio de la ciencia y, desde allí, colabora en el desarrollo de la historia.
\end{abstract}

Palabras-claves: Ciencia; Literatura; Historia.

\begin{abstract}
Like many Argentine doctors from the late nineteenth century, Francisco Sicardi writes a series of novels, organized in "Strange book" (Libro extraño, 1902). The last novel in the series entitled "Towards justice" ("Hacia la justicia") and raises José Ingenieros's critics. This novel presents a detailed picture of the Buenos Aires society, with its most characteristic types, agreeing with some of the principles of naturalism. Ingenieros recognizes these characteristics, but his criticism is lapidary: when he must propose a resolution to the political conflict, the author abandons the science, betrays the principles of naturalism and offers the history to an illusion's intervention. In our work we analyzed the Ingenieros's review, trying to recognize its meaning and its importance. We consider some contributions of literary naturalism in his argument, but warned that the central concern of this author lies in the link between science and history. The literature is at the service of science, and from there contributed with the history development.
\end{abstract}

Keywords: Sciences; Literature; History.

Artigo recebido em: 27/07/2014

Artigo aprovado para publicação em: 19/11/2014

\footnotetext{
${ }^{1}$ Docente de la Universidad Nacional de Córdoba. IDACOR-CONICET. Profesora y licenciada en Filosofía por esa Universidad y doctora en Ciencias Sociales y Humanas por la Universidad Nacional de Quilmes. Titulo de la investigación en curso: "La definición y el rol de la filosofía en la formación de la cultura nacional en las primeras décadas del siglo XX. Un recorrido por la Revista de Filosofía". Financiamiento: CONICET. E-mail: carlagalfione@yahoo.com.ar.
}

\section{GANPHLAC}

Revista Eletrônica da ANPHLAC, ISSN 1679-1061, N. 17, p. 235-253, jul./dez. 2014.

http://revista.anphlac.org.br/ 
El novelista no es más que un escribano que no juzga ni saca conclusiones. . . el novelista desaparece, guarda para sí sus emociones, expone simplemente las cosas que ha visto [...] La intervención apasionada o enternecida del escritor empequeñece la novela, velando la nitidez de las líneas, introduciendo un elemento extraño en los hechos que destruye su valor científico.

E. Zola, La novela experimental

Al comienzo de un breve texto, escrito en 1902 y titulado "Hacia la justicia", el escritor argentino José ingenieros afirmaba: "una mala disimulada esclavitud oprime a los médicos intelectuales. La opinión pública tiende a estrechar su horizonte, desdeñando a los que para distraerse del tedio de las clínicas buscan inocentes pasatiempos en las ciencias sociales o en las letras puras" (1957, p. 55). Esa generalización es, sin embargo, más que la denuncia de una sociedad que no da lugar a la conciliación del arte con la ciencia, una expresión provocadora, que sirve de puntapié inicial a la problematización de un vínculo generalizado en la práctica de los médicos locales, ante el cual, sin embargo, Ingenieros encuentra ciertos desperfectos.

El texto al que nos referimos versa en torno una obra de Francisco Sicardi, titulada, precisamente, "Hacia la justicia" y publicada en Buenos Aires en 1902 como parte de una obra mayor que será titulada por sus lectores "Libro extraño". ${ }^{3}$ El autor de esa obra debe contarse dentro de ese conjunto en absoluto acotado de médicos argentinos, en su mayoría porteños, que hacia fines del siglo XIX complementan su labor científica con la escritura de algunas obras literarias. Él es parte, como afirma Ansolabehere (2005, p. 544), de "la nutrida camada de médicos-escritores que irrumpe en la literatura argentina desde 1880", entre los que comúnmente se destacan los nombres de Eugenio Cambaceres, Eduardo

\footnotetext{
${ }^{2}$ Nos atenemos al texto de Ingenieros llamado "Hacia la Justicia" en la edición de 1957, pero advertimos que éste lleva una nota de Aníbal Ponce en la que afirma que este trabajo habría sido inicialmente, en 1902, publicado con el título "La psicopatología en el arte".

${ }^{3}$ Libro extraño reúne un conjunto de escritos publicados entre 1894 y 1902, en los que se relata una historia familiar con personajes típicos del escenario urbano de ese fin de siglo. "Hacia la justicia" es el último relato, culminación de la obra y, en ese sentido, no es casual que sea el objeto del trabajo de Ingenieros, pero volveremos a esta cuestión sobre el final. Graciela Salto recuerda que fue Lucio V. Mansilla quien consideró "raro" el texto de Sicardi, y da cuenta de la recepción que tuvo el texto entre el público general y entre la elite.
}

\section{GANPHLAC}

Revista Eletrônica da ANPHLAC, ISSN 1679-1061, No. 17, p. 235-253, jul./dez. 2014.

http://revista.anphlac.org.br/ 
Holmberg o Antonio Argerich, algunos de los principales representantes de ese nada inusual encuentro entre la literatura y la medicina.

A pesar de la tan reconocida frecuencia con que se ligaban en la época la ciencia, y en particular la medicina, con la literatura, Ingenieros presenta ese trabajo de Sicardi marcando la falla. Hay algo en esa conjunción que molesta a la opinión pública, tanto es así que considera mejor ocultar el nombre del autor del texto que comenta para "no perjudicarle". Se trata, no obstante, de un provocativo afán de proteger a un colega cuyo escrito estaba, no obstante, en boca de algunos de los más reconocidos escritores del momento que, a los pocos meses de haber sido publicado, lo discutían en las páginas de La Nación ${ }^{4}$. Una poco convincente afección, ya que, como sostiene Horacio González al comentar este texto, es escasamente probable que en la Buenos Aires de Argerich, de Rawson, de Wilde, de Ramos Mejía, hubiera sido comprometedora la referencia explícita al autor de la novela (GONZÁLEZ, 1999, p. 31). ${ }^{5}$

Los recursos retóricos de nuestro autor nos hablan mucho más de sus diferencias con Sicardi, que de un efectivo problema de la escritura literaria hecha por médicos. La pregunta que surge entonces es acerca de lo que ve Ingenieros en esa obra, cuál es el verdadero objeto de la crítica de Ingenieros. Aclararlo nos permitirá reconocer cómo entiende un médico, interesado por la criminología, la psicología y, luego, por la sociología, el rol que debe jugar la literatura en la comprensión del presente y, en función de esto, cuáles deben ser los rasgos más convenientes a este tipo de escritura.

Lo que, entendemos, aparece en esta tematización de Ingenieros a propósito del texto de Sicardi es, primero, su preocupación por mantener a las ciencias en el centro de la escena a la hora de pensar las reformas sociales y las definiciones de políticas de intervención social, con la profunda reforma del modelo de las ciencias y de la política que ello supone, y, segundo, derivándose de lo anterior, el reclamo de armonización de esos aportes de la ciencia con la literatura. Dicho de otra manera, Ingenieros estaría advirtiendo

\footnotetext{
${ }^{4}$ Salto destaca los comentarios que Mansilla, Groussac y Christian Roeber publicaron en el periódico (SALTO, p. 6).

${ }^{5}$ González afirma que Ingenieros estaría aquí ensayando lo que él considera una "nueva crítica", cuyo rasgo principal se deriva de su vinculación con la ciencia.
}

\section{GANPHLAC}

Revista Eletrônica da ANPHLAC, ISSN 1679-1061, Nº 17, p. 235-253, jul./dez. 2014.

http://revista.anphlac.org.br/ 
algo que algunos de sus contemporáneos también descubren aunque con inclinaciones políticas diversas: el inmenso poder cultural y político de la literatura y la necesidad de normalizarla.

En lo que sigue analizamos de cerca el texto de Ingenieros, intentando extraer de allí diferentes elementos que nos permitan reconocer en qué medida el pretendido vínculo entre literatura y ciencia supone, primero, la conciencia del lugar que comienza a ocupar la literatura en la construcción simbólica de la nación y, segundo, la determinación de un conjunto de condiciones que aquella deberá reunir para poder, al servicio de la ciencia, contribuir al logro de los ciertos objetivos históricos. La literatura puede ser un relato de la historia, puede armonizar con la historia pasada y por pasar, pero ello sólo en la medida en que reconoce y respeta a la ciencia como mediadora.

\section{La novela}

La crítica de Ingenieros al texto de Sicardi oscila entre la valoración de ciertos elementos y la denuncia de importantes carencias. En la novela, según su descripción, hay una "desconcertante erupción de arte y de vida". Se presentan "tipos vibrantes de intensa vida artística", "la paleta imaginaria parece haber derrochado tonos de calurosa vividez [sic]; gamas complejas de colores son percibidas incesantemente, como vaporosa y fecunda emanación de una naturaleza en orgiástica vitalidad”, y sin embargo, agrega más adelante: "la intimidad de las sensaciones no es uniforme; como caídas entre las pinceladas hermosas, se descubren brochazos de blanqueador que parece ocupado de sus tareas al compás de un organillo" (INGENIEROS, 1957, p. 57).

El modelo de Sicardi, tal como lo lee Ingenieros, y también el que se usa para medir a Sicardi, es, entre otros, aunque principalmente, Émile Zola, quien, según el crítico, supo trasuntar en sus obras "el momento contemporáneo de la sociedad en que vivió". 6 Sicardi,

\footnotetext{
${ }^{6}$ Esta referencia de Ingenieros a Zola, sumado al cientificismo que impregna toda su producción durante los años cercanos a su lectura del texto de Sicardi, nos permite suponer que Ingenieros no sólo conoció las obras de autor francés sino que estuvo al tanto de algunos de los debates acerca de la relación entre las ciencias experimentales y la literatura. Sobre éstos es interesante revisar el texto de Rafael Huertas García-Alejo, "La 'novela experimental' y la ciencia positivista" (2013).
}

\section{GANPHLAC}

Revista Eletrônica da ANPHLAC, ISSN 1679-1061, No. 17, p. 235-253, jul./dez. 2014.

http://revista.anphlac.org.br/ 
para nuestro autor, ha querido parecerse al francés y puede haberlo logrado en lo que hace a la descripción de la sociedad y sus costumbres y de los perfiles psicológicos de sus personajes. "Los protagonistas de Libro extraño pretenden haber sido observados en la realidad, se relacionan y se continúan, transmitiéndose sus virtudes y sus vicios, con la misma inviolable fatalidad psicológica que gravita sobre los personajes de Zola" (INGENIEROS, 1957, p. 58). En esto, juzga el crítico, se ha manifestado como un verdadero artista y ha ostentado su virtuosismo para mostrar lo real.

Si atendemos a la novela, vemos que, efectivamente, prima allí el tono de una descripción cuidada, plagada de detalles y de vida, acorde con el modelo del naturalismo. Ella ofrece un completo fresco de la sociedad porteña del momento, de sus tipos más característicos y de sus conflictos. Allí se pintan, sin ahorrar pormenores, las condiciones de vida de la clase obrera: la pobreza, la explotación y el sufrimiento, y se percibe un manifiesto interés por dar cuenta de los rasgos más finos de ese cuadro de dolor. Así, la novela hace sentir la muerte que recorre las calles y los cuerpos. Desde un comienzo, y derivándose del cuadro de las injusticias sociales que da inicio a la obra, vemos a la muerte pasearse entre los personajes:

\footnotetext{
hace meses que el cielo de plomo quiebra sus dorsos -los dorsos de los trabajadores-, hace meses que llueve y que las compañeras de los pobres tienen tristezas. A lo lejos asoma el hambre con su máscara de espectro y camina a saltos haciendo crujir las canillas. Sus largos bazos y sus manos de esqueleto echan por delante generaciones enteras de demacrados que aúllan con lúgubres lamentaciones y piden pan (SICARDI, s/f, p. 410).
}

La mirada de muerte que lo devora todo es también la del narrador que mira y describe casi sin adjetivaciones, que se apropia de una atmósfera que espera ser captada con precisión. Hay en estas páginas, dice Ingenieros, "sentimentalismos místicos e idealismo demoledores, brazos que arrojan la bomba o levantan el crucifijo, turbas de alma ardiente como el incendio, arrebatada como el huracán" y por eso, agrega, es un libro que "aspira a reflejar la vida entera de nuestro pueblo en un momento dado de su evolución" (INGENIEROS, 1957, p. 59).

\section{GANPHLAC}

Revista Eletrônica da ANPHLAC, ISSN 1679-1061, No. 17, p. 235-253, jul./dez. 2014.

http://revista.anphlac.org.br/ 
Ahora bien, ese es el escenario pero no el tema de la obra, y, del mismo modo, tampoco reside allí el problema que desaprueba y denuncia Ingenieros. Sicardi no se conforma con la fotografía. Ante la atmósfera de muerte, denuncia la necesidad de hacerle frente, pero al hacerlo convocaría, según el crítico, a fuerzas que exceden lo natural. A juicio de Ingenieros, Sicardi vivifica el cuadro contrariando la fría descripción e introduciendo las pasiones, los deseos y la voluntad. Allí es, precisamente, donde sus personajes se pertrechan de armaduras que parecen ser poco reales o poco convincentes, allí es donde la realidad parece forzada por la literatura.

Haciendo una rápida descripción de la novela, con el objetivo de comprender el sentido de la crítica de Ingenieros, podemos decir que en ella se enfrentan tres tipos de individuos: el anarquista, el católico y el pacifista. ${ }^{7}$ El anarquista está personificado en Germán Valverde, anarquista por herencia, que junto a su compañera Goga, una prostituta que nunca conoció a su madre y que parece actuar bajo la sugestión de aquél, recorren las fábricas exaltando a los obreros, llamándolos al abandono de los talleres, a tomar la calle, a atacar a sus adversarios y a apoderarse de sus bienes que son hasta hoy las herramientas de la opresión. El católico se presenta con diferentes matices en las figuras de Dolores Del Río, Angélica y Ricardo Méndez, esposa e hijos del fallecido médico Méndez. En ese grupo, Dolores y Angélica se constituyen como lo más sano de la familia, fundiendo la maternidad, con la estirpe criolla y el dominio de la lengua española, mientras que Ricardo, fiel a la herencia psicopatológica de su padre, mostrará signos de de cierta disfuncionalidad psíquica. Católicos, devotos y piadosos, estos personajes, hacen de la caridad el principal objeto de su vida. En Dolores y Angélica el catolicismo es la expresión de un equilibrio anímico singular, mientras que en Ricardo se liga con el sectarismo político transformando aquel amor en odio sin clemencia. Ellos son dueños de "la casa de amplios corredores", antigua posesión de la familia criolla Del Río, en torno a la que transcurre, como alegoría

\footnotetext{
${ }^{7}$ Recordemos que "Hacia la justicia" es la última novela de la serie y que los personajes de ésta ya han aparecido en las anteriores, aunque Ingenieros no considere ni recuerde en ningún momento esos otros textos. Es importante tener presente aquí el trabajo que ya mencionamos de Gabriela Nouzeilles, allí la autora recorre el conjunto de la obra de Sicardi y reconstruye los tipos de personajes que se van desplegando a lo largo de la misma. En ese análisis se observan detalles importantes que complejizan la tipificación que proponemos aquí.
}

\section{CANPHLAC}

Revista Eletrônica da ANPHLAC, ISSN 1679-1061, Nº 17, p. 235-253, jul./dez. 2014.

http://revista.anphlac.org.br/ 
contundente de la patria, la obra en su totalidad. En el comienzo, sirve de cobijo para la muchedumbre que, humilde y sin fuerza, deambula bajo la lluvia huyendo de la inundación que se lo ha llevado todo, pero es también, hacia el final, blanco de los ataques de la multitud enfurecida y exaltada por las exhortaciones del anarquista.

El tercer tipo, el del reformador social, el pacificador, toma cuerpo en Elbio, un médico nacido en una familia de inmigrantes vascos, humilde y asediada por el hambre, acosada por la naturaleza misma que, en la "gran inundación", produjo la muerte de uno de los suyos, el hermano de Elbio. Elbio es fruto de la convicción y del trabajo de su padre, Martín Errecart, un esforzado carpintero. Modelo del trabajo y del estudio, Elbio será, en las páginas finales, el encargado de salvar cuerpos y almas ${ }^{8}$. Elbio condena el sufrimiento de los pobres, pero repudia tanto la violencia anarquista, cuanto la caridad cristiana. Sólo confía en el Estado que, descripto por Sicardi, "ya no es enemigo de los trabajadores, sino que es su corolario, una emanación de su fuerza” (SICARDI, s/f, p. 588).

Detrás de esos personajes y esos tres modelos se asoma, incisiva, la multitud, un personaje colectivo que nunca se pierde de vista y que siempre permanece expectante para entrar en escena. Allí Ingenieros recuerda emocionado las imágenes de Germinal, "son páginas de maestro -dice- que apasionan y caldean" (INGENIEROS, 1957, p. 71). En todo enfrentamiento, la masa ocupa el escenario, es el complemento necesario para intensificar cada acto; su marcha, sus gritos, dan fuerza a la novela.

Aquí se hace evidente cómo la caracterización de esta masa, al igual que la de los otros personajes, revela la fuerte presencia de las coordenadas positivistas que no se limitaban al trabajo de laboratorio sino que pretendían extenderse al campo de la literatura. Cada uno de los personajes parece querer ser descripto de acuerdo a los modelos que ofrecía por entonces la biología, en diálogo con los primeros desarrollos de la psicología y de acuerdo también con los elementos que estas ciencias ofrecían para la elaboración de

\footnotetext{
${ }^{8}$ Es interesante ver que en la caracterización que hace Ingenieros de Elio, no es un dato menor su ascendencia. Elbio es, dice, hijo de "el viejo sano y laborioso, el obrero de ayer que ha llegado a tener un buen pasar y enaltecer el apellido con el doctorado filial; un pequeño burgués que, sin ser reaccionario, no ha pensado mucho en las posibilidades de una trasmutación social" (INGENIEROS, 1957, p. 65).
}

\section{GANPHLAC}

Revista Eletrônica da ANPHLAC, ISSN 1679-1061, Nº 17, p. 235-253, jul./dez. 2014.

http://revista.anphlac.org.br/ 
ciertas definiciones sociológicas. ${ }^{9}$ De este modo, los personajes de la obra alegorizan las principales características de la sociedad porteña de entonces.

A través de esos tipos de individuos, de sus encuentros y enfrentamientos transcurre la novela. El choque entre ellos está latente pero el final llega sin que sea el enfrentamiento la causa de la caída de unos y el triunfo de otros. Germán es el primero en morir, pero no muere en manos de los otros personajes, muere por sí mismo, por su propio destino, muere una muerte que llevaba dentro desde su primera aparición en escena. Su padre, al morir, le dejó una carta que se transcribe al comienzo de la obra. En ella le mostró la miseria y lo obligó a odiar a los hombres y a hacerse anarquista. Esa es su muerte. Su muerte es producto de una enfermedad fatal que carcome el cuerpo desde dentro y desde siempre. Y en el momento final, es precisamente de su boca, que es su principal arma de lucha, de donde brota su sangre, que es su herencia y que es su muerte. ${ }^{10}$

Goga, su compañera, también muere. Pero muere en la casa de los amplios corredores, esa que es refugio de los humildes, y de la mano de Dolores, una madre. Con la muerte, tiene casa y madre. Ante ese mundo viejo y nuevo a la vez de los católicos, de muerte y vida en constante juego, Goga, víctima de la sugestión permanente, cae bajo el efecto de una nueva fascinación que esta vez la pacifica y la reconcilia con los hombres. Su

\footnotetext{
${ }^{9}$ Este tema, el de los aspectos cientificistas o positivistas de la obra de Sicardi, si bien constituye un tema de sumo interés que se extiende en relación con el tópico de la locura y de la sugestión, del tratamiento de los problemas sociales y de la delincuencia política, de las masas y de la mujer, excede las pretensiones de este trabajo que se reduce a la lectura de Ingenieros. Sobre esos temas en la obra de Sicardi son escasos los trabajos desarrollados, pero se destacan el de Graciela Salto, mencionado arriba, y el de Vanesa Mara Pafundo y Javier Elías Bortz, "De libros extraños a médicos extraños. El caso Sicardi” (2013).

${ }^{10}$ El texto Pablo Ansolabehere sugiere esta idea. Allí el autor dice: "Germán muere por la boca, por el lugar donde sale su voz blasfema, esa voz a través de la cual fue presentado el personaje en el relato, una voz capaz -como su sangre, por su sangre- de "manchar todo lo puro" y de fascinar a la muchedumbre hasta convertirla en horda, en esa "enfermedad convulsionaria" llamada huelga". No obstante, puede verse junto a esta centralidad otorgada a la herencia, como rasgos fisiológico determinante del comportamiento del individuo, otro aspecto también determinante en un modelo naturalista: el medio. La carta que Germán recibe de su padre y que despertaría el odio hacia los hombres es un minucioso detalle de los males y el sufrimiento en los que viven las masas de inmigrantes en los suburbios porteños. Esa descripción ocupa un lugar importante en la novela, que se complementa con las diferentes imágenes que se ofrecen de esa masa exaltada por el anarquista o por Goga, y que complejiza bastante el cuadro de los elementos determinantes de la reacción de éstos. Respecto de la herencia que recaería sobre Germán es interesante revisar el trabajo de Nouzeilles en el que se analizan las principales características del modelo que presenta el padre de Germán, esbozadas en las otras partes de la obra. (Cf. NOUZEILLES, 2000, p.233).
}

\section{CANPHLAC}

Revista Eletrônica da ANPHLAC, ISSN 1679-1061, No. 17, p. 235-253, jul./dez. 2014.

http://revista.anphlac.org.br/ 
muerte es una entrega sin lamentos hacia esa nueva vida, oponiéndose a la vivacidad y la energía que caracterizaba al personaje bajo el dominio del anarquista. Su agonía dura sólo el tiempo necesario para la conversión. Pero lo más importante aquí es el origen de su muerte. Goga no muere por herencia, muere por sugestión; muere también presa de una fuerza que no controla, muere por la mano del anarquista. Es Germán, que en otro momento la había salvado, y no un católico ni un reformista, el que lanza la daga que se hunde en su pecho mientras ella, bajo un nuevo furor, intenta defender la casa de los católicos. ${ }^{11}$

El resto de los personajes, excepto Dolores que muere hacia el final sin enfermedad y sin sufrimiento, logran en ese final conciliar sus diferencias y habitar en una misma casa, la de amplios corredores, con nuevas familias. Elbio se casa con Angélica ante el sacerdote, poblando con un nuevo nombre, el del inmigrante trabajador, la antigua casa. En esa casa encontrará finalmente su lugar la unión armónica del inmigrante y la oligarquía criolla. Pasado por el tamiz del orden y el trabajo, el inmigrante es la fuerza nueva que hace fecunda la nación argentina: de la unión de Elbio y Angélica nacerán dos niños "sanos y robustos" que serán "honestos y laboriosos", la base de una nueva familia (SICARDI, s/f, p. 619). Pero la intervención de Elbio no es sólo biológica y cultural, es también y de manera explícita, política. El hijo del inmigrante vasco termina por ocupar un lugar en el parlamento para cumplir con la misión de su "alma buena": luchar por "felicidad de los trabajadores, por la mejor salud y el salario más alto" (SICARDI, s/f, p. 615).

\section{Literatura e ilusión}

Contra la pasión del cuadro, que muestra lo real por todos sus poros, dijimos, Ingenieros denuncia la debilidad de ese final, que es poco convincente y, sobretodo, poco real. La necesidad de resolver los conflictos que se tejen a lo largo de la novela parece llevar al autor a tomar algunas decisiones que contrastan con la realidad de la escena. En

\footnotetext{
${ }^{11}$ Dijimos que excedía las posibilidades de este texto el hacer una lectura del sentido de las imágenes que ofrece Sicardi, pero puede ser interesante simplemente advertir aquí que la muerte de Germán y Goga es en ambos casos patológica, fatal y causada, al mismo tiempo, por los mismos anarquistas sin intervención de los otros tipos. Con esto es evidente que Sicardi intenta identificar el anarquismo con lo patológico y, desde allí, advertir el peligro que éste conlleva.
}

\section{CANPHLAC}

Revista Eletrônica da ANPHLAC, ISSN 1679-1061, No. 17, p. 235-253, jul./dez. 2014.

http://revista.anphlac.org.br/ 
eso se cifra el sentido de la crítica lapidaria que Ingenieros arroja contra la obra de Sicardi: "Elbio es un socialista moderado que no entusiasma ni irrita" (INGENIEROS, 1957, p. 71). El telón cae sobre esa figura desanimada, poco real, ilusa, y el juicio cae sobre toda la novela. Con Elbio, en el final, la novela pierde su fuerza y su verdad. Se pretende a Elbio un personaje consciente, pero pierde su inteligencia desde el momento en que cree que son sus valores y no su ciencia las que podrían guiar la historia. La descripción falla, a juicio de Ingenieros, porque se deja de lado la ciencia, la ciencia del propio Sicardi y la ciencia de Elbio, porque se pierde la lucidez. Y con ello, al desplazarse ese saber, se pierde la distancia necesaria entre el que mira y su objeto, entre Elbio y esa sociedad que espera ser legislada. Se pierde también la distancia del observador que le permitía a Sicardi ofrecer un cuadro fiel a lo real. En Elbio y en Sicardi se interpone la quimera, y la que pierde es la ciencia.

El abandono de esa escritura atenida a lo real es, en el juicio de nuestro autor, el defecto mayor de esta obra que se aleja, desde ese momento, de toda posibilidad de tratar la cuestión social. Para Ingenieros, "la realidad social no es accesible por el método de la adivinación, ni por sentimientos de simpatía que exponen a caer en ingenuidades”, y en ese marco sostiene que "el autor, lo mismo que su Elbio, aparece como un ingenuo 'socialista vergonzante', sin saberlo ni desearlo, poco tiene de reformador o de sociólogo, mucho de lírico metafísico" (INGENIEROS, 1957, p. 71).

En el fondo de la crítica se adivinan dos elementos íntimamente ligados que pueden reconocerse como estructurantes de las nociones desarrolladas por Ingenieros en los años cercanos al texto que comentamos. Se ligan aquí una visión del conocimiento y una mirada de la historia. En el primer sentido, el abandono por parte de Sicardi de esa mirada inicial de un relator omnisciente es, además de un distanciamiento respecto del naturalismo -que puede leerse en clave histórico-literaria- un retroceso en el campo epistemológico porque supone un rechazo de los presupuestos de la ciencia en la que tanto confía Ingenieros. Se abandona la descripción que se deriva directamente de la observación, se deja de lado el poder de "reflejar", junto a la objetividad que éste ofrecía, y se adoptan formas "precientíficas" que hacen de la verdad el producto de las divagaciones humanas. Es contundente la crítica de Ingenieros ante esta ausencia de método y de ciencia. Tal como lo

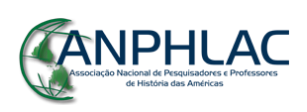

Revista Eletrônica da ANPHLAC, ISSN 1679-1061, Nº. 17, p. 235-253, jul./dez. 2014.

http://revista.anphlac.org.br/ 
lee nuestro autor, Sicardi abandona la descripción y elige, en cambio, ya lo mencionamos, “el método de la adivinación”. Lo cual no puede ser entendido más que como un retroceso, como un regreso a aquella era de la potestad transformadora de los hombres, en que la sola voluntad bastaba para direccionar la historia. Desde ese punto de vista, la novela, que hacía en el comienzo algunos guiños al científico, lo decepciona al encarnar el vínculo entre literatura y ficción.

Por su parte, la mirada de la historia que denuncia nuestro autor se ata directamente con la visión del método. En la obra de Sicardi, Ingenieros observa un forzamiento del sentido de la historia, que desconoce la explicación contemporánea y científica del devenir histórico para ampararse en un esquema previo, ilustrado. Mientras que en el final de "Hacia la justicia" el curso de la historia es presentado como el producto de la razón y la virtud humana que se hacen carne en la figura de Elbio, Ingenieros, inmerso en el modelo por momentos naturalista y por momentos materialista, entiende la historia como devenir necesario de la evolución que se deriva del perfeccionamiento de las técnicas de producción en la lucha del hombre con la naturaleza. En las antípodas, ignorante del determinismo de la historia y ciego ante el "ritmo de la experiencia social", Sicardi habría abandonado el pincel del artista para asirse de la brocha del blanqueador, adormecido por el compás de un organillo. Sicardi pretendió sujetar la historia y sus conflictos al "iluso pacificador que arreglara todos los entuertos sociales mediante cuatro decretos políticos, como quien cambia las bambalinas de un escenario, mientras los espectadores se aburren en el entreacto" (INGENIEROS, 1957, p. 73). Y de este modo, transformó su novela una obra de la ficción.

La "cuestión social", o los problemas de índole social y política, deben, para el crítico, ser comprendidos dentro de ese movimiento natural y la resolución de los conflictos no puede sino ser consecuencia del movimiento lento y evolutivo de la historia. La solución de Sicardi, en cambio, resulta ser un intento de librarse del poder determinante de la historia y es por ello un forzamiento de lo real. Aquí se acabaría el naturalismo del pretendido artista y con ello sus posibilidades de decir alguna verdad. Nos encontramos así ante una de las modificaciones que, según Gabriela Nouzeilles (2000, p. 229), presenta la

\section{GANPHLAC}

Revista Eletrônica da ANPHLAC, ISSN 1679-1061, No. 17, p. 235-253, jul./dez. 2014.

http://revista.anphlac.org.br/ 
obra de Sicardi respecto de la dinámica del argumento naturalista: la relativización del éxito de la práctica médica. ${ }^{12}$ Algo que, tal como lo comprende esta autora, se elabora en función de la sobrevaloración del modelo evolucionista que llevaría al autor a aceptar el orden natural como implacable sin lugar para la intervención humana; pero que puede también ser leído, siguiendo a Ingenieros, de manera contraria: como denuncia de la soberbia afirmación de un poder ilimitado de transformación propio del hombre. ${ }^{13}$

Contrario a lo que se derivaría de ese final, para Ingenieros:

el desarrollo progresivo -propio de las sociedades humanas- tiende a elevar el bienestar medio de los individuos en la sociedad pero ese resultado [...] no es simultáneo para todos los hombres, formándose clases privilegiadas y clases desposeídas. La lucha entre las clases, para la elevación del bienestar colectivo, determina los conflictos sociales, independientemente de las personas que en ellos actúan y pueden tener la ilusión de motivarlos (INGENIEROS, 1957, p. 72).

Y se agrega más adelante: “no se puede marchar 'hacia la justicia' con sólo cambiar los sentimientos de las personas, lo indispensable es que se transformen las instituciones que hacen posible la injustica" (INGENIEROS, 1957, p. 73), algo que depende exclusivamente del perfeccionamiento de las técnicas de producción para alcanzar la socialización de las fuerzas productivas. Allí radica la verdadera justicia. Los conflictos sociales no son conflictos entre personas o entre sectas, como pretende decir Sicardi, son producto del conflicto de intereses económicos encontrados y las luchas sociales son expresión de "conflictos económicos profundos".

\footnotetext{
${ }^{12}$ Pueden reconocerse, tal como lo hace Gabriela Nouzeilles (2000, p. 228-229), particularidades en la novela que exceden las características más básicas del modelo naturalista, tales como la posibilidad de ampliar los planos narrativos dando lugar al plano de la "raza nacional", la multiplicación de las historias eróticas y la escasa confianza en el saber médico como saber regenerador. Si bien es cierto que la autora trabaja sobre toda la novela Libro extraño, y que alguno de estos elementos puede no reconocerse de manera contundente en el último libro, esta caracterización vale en términos generales también para este libro y, en particular, el último de los aspectos destacados por Nouzeilles se vincula directamente con la crítica que la obra recibe de Ingenieros.

${ }^{13}$ Aclaremos que, por su parte, Ingenieros, fiel al argumento naturalista, cuestiona aquí, no la posibilidad de la intervención en el curso de los acontecimientos, sino el sentido, el fundamento y las características de esa capacidad.
}

\section{GANPHLAC}

Revista Eletrônica da ANPHLAC, ISSN 1679-1061, No. 17, p. 235-253, jul./dez. 2014.

http://revista.anphlac.org.br/ 


\section{Literatura y ciência}

Ahora bien, la atención que dirige Ingenieros al método y el modo en que concibe la historia y su movimiento ¿hacen suponer en él el reclamo de una distancia entre la literatura y la cuestión social? ¿La distancia que se marca entre la novela de Sicardi y su posibilidad de ofrecer una lectura correcta de los fenómenos sociales y políticos debe extenderse a toda la literatura? Ingenieros no es escritor literario y mucho menos crítico, pero es posible suponer que, en los años que escribe la crítica a Sicardi, ya ha elaborado las bases de un modelo que le servirá para leer el conjunto de los fenómenos humanos e históricos sobre las que avanzará minuciosamente años después y que ese modelo le dará las herramientas para posicionarse en lo que concebirá como uno de los elementos centrales de toda civilización: la cultura. Aunque nunca llegue a ocuparse de literatura, al parecer un campo vedado o, al menos, en disputa para este médico, sí reconocerá y reclamará la posibilidad de establecer un vínculo estrecho entre ésta y la ciencia y, a través suyo, la historia. En el modelo de Ingenieros, la "cuestión social" debe ser entendida como una cuestión científica y la literatura que intente representarla deberá atenerse a los principios de la ciencia. Tanto su forma como su contenido deberán ser acordes al método científico, del mismo modo que cualquier otro saber.

Se vuelve sugerente aquí cierta cercanía del planteo de Ingenieros con los rasgos más sobresalientes de la literatura naturalista francesa. Describiendo esos rasgos, dice Lukács: "el método de la observación y de la descripción surge con la intención de volver científica a la literatura, transformándola en una ciencia natural aplicada, en una sociología” (LUKÁCS, 1977, p. 63). Algo que está presente en el reclamo de Ingenieros. Habiendo ligando a Sicardi con Zola en un principio, la constatación del parentesco se interrumpe en el momento en que comienza la crítica. Sicardi abandona el realismo al introducir la ficción de un hombre que puede cambiar el mundo y con ello renuncia al vínculo entre literatura y ciencia, condenando la literatura. Zola no es más el modelo de Sicardi, sino una vara para medirlo. Pero es, en cambio, para nuestro autor, el modelo por excelencia de toda

\section{GANPHLAC}

Revista Eletrônica da ANPHLAC, ISSN 1679-1061, N. 17, p. 235-253, jul./dez. 2014.

http://revista.anphlac.org.br/ 
descripción que pretenda dar cuenta de la cuestión social y es gracias a ese modelo que puede juzgar al médico-literato argentino.

La literatura que describe y que valora Ingenieros no es una literatura que invita al lector a vivirla, a compartir con los personajes las sensaciones que nacen de su participación en acontecimientos que se presentan como muy significativos para ellos y para los grupos de los que forman parte. La literatura, en cambio, tiene como objetivo presentar los acontecimientos objetivamente y por lo tanto no le corresponde contar ni con la pasión de los personajes ni con la identificación del lector. No hay modelos a imitar, sus personajes son simples seres vivos -quizás, sólo cuerpos con vida- que transitan un medio en el que deben sobrevivir, y sus acciones, las estrategias necesarias de adaptación y/o simulación para lograr el objetivo. El lector de la novela sólo debe observar, conoce a sus personajes a fuerza de observarlos y por eso vale la literatura ${ }^{14}$.

Decía Lukács de este modelo, que cosificaba, que transformaba lo representado en naturaleza muerta. Y efectivamente, aunque con otra valoración, es así en el esquema de Ingenieros: la fría descripción de esa naturaleza, mиerta porque carece de pasiones que afecten nuestra sensibilidad, es pasible de ser captada por el ojo del microscopio, aunque, paradójicamente, su objetivo sea entender, a través de ella, la vida. Ingenieros invierte el orden de las valoraciones, poniendo la vida en la naturaleza que persiste antes que en la potencialidad realizadora o transformadora de hombres racionales. Y con ello, se hace evidente una paradoja: en el relato, Sicardi contrapone hacia el final la muerte del anarquista a la vida del pacifista. Sin embargo, precisamente en ese desenlace Ingenieros descubre la debilidad de la novela. Elbio es, para él, un ser inanimado. La falta de vida aleja la novela de la mirada del científico que -aunque Lukács sostenga lo contrario- pretendía, a partir de ella, entender la vida. No hay más que vida, y ésta se define como lucha por la supervivencia. Su conocimiento es condición para definir cualquier modelo de intervención política. Porque, al contrario, una política que no se piense en relación a la vida es para él

\footnotetext{
${ }^{14}$ Sobre la cuestión de la relación entre ciencia y literatura ya hemos mencionado la importancia del trabajo de Rafael Huertas García-Alejo, "La `novela experimental' y la ciencia positivista”.
}

\section{GANPHLAC}

Revista Eletrônica da ANPHLAC, ISSN 1679-1061, No. 17, p. 235-253, jul./dez. 2014.

http://revista.anphlac.org.br/ 
una ficción peligrosa: desconoce la historia y está encerrada en las sugestiones del modelo burgués o moderno que sólo la reconoce como obra de héroes.

Ese es el aporte de la literatura, en tanto se atiene al método de la descripción. Aporta al conocimiento del objeto por parte del científico social y con ello contribuye en la definición de un modo de intervención política que ya no puede pensarse como producto de las libres voluntades o los destinos humanos, sino que, resultado del estudio minucioso, sociológico y psicológico, de los factores que convergen en el movimiento natural de la historia, es una política que tiene por objetivo el diseño de instituciones para la detección y reforma de los obstáculos que se interpongan a dicho movimiento. ${ }^{15}$

Decía Ingenieros (1957, p. 74):

los hombres que ignoran el ritmo de la experiencia social no pueden prever el curso de los sucesos en la sociedad de que forman parte, ni modificar con ideas inexactas la marcha de la humanidad. Esta marcha, al reflejarse en la mente de los hombres ilustrados, produce ideas que permiten interpretar el pasado, tener conciencia del presente, presentir las líneas generales del porvenir.

Y aquí es donde nos encontramos con la "cuestión social”, principal preocupación del juicio de Ingenieros sobre el texto de Sicardi: las derivas prácticas de una reflexión epistemológica. Elbio es iluso, es ignorante, no conoce las manifestaciones de la experiencia social, y por ello niega los conflictos, acallándolos bajo un discurso bienintencionado. No mira al "obrero real" y no reconoce que la historia se hace de sus luchas, de los enfrentamientos entre hombres con "intereses económicos inconciliables". El científico, en cambio, que presiente ese porvenir, lo descubre luego de la observación detenida del presente y, si es acaso posible que intervenga en ese futuro, ello sólo es así

\footnotetext{
${ }^{15}$ Cabe aclarar aquí que la obra de Ingenieros no es uniforme y puede verse en ella algunos desplazamientos teóricos a través de los que el autor hace lugar tanto a sus diversas miradas de la historia y la sociedad contemporánea, cuanto a sus diferentes posiciones políticas. Sin embargo, aunque los actores protagonistas de la historia vayan cambiando, sean por momentos los obreros y por momentos una aristocracia intelectual, es muy recurrente su oposición a modelos teórico-políticos que pretendan hacer de la historia la obra exclusiva de la acción de hombres libres, porque advierte que la noción de libertad es sólo la invención de un grupo social para alcanzar y mantenerse en el poder. En ese sentido, es constante a lo largo de su corta vida intelectual su distancia política con la burguesía, con los "reptiles burgueses", en La Montaña, y con el "hombre mediocre", en el texto de 1913. En ese sentido también debe leerse la crítica a Sicardi.
}

\section{GANPHLAC}

Revista Eletrônica da ANPHLAC, ISSN 1679-1061, No. 17, p. 235-253, jul./dez. 2014.

http://revista.anphlac.org.br/ 
porque ha descubierto lo conflictivo de la historia y del presente, porque se ha enfrentado con lo real sin forzar conciliaciones. ${ }^{16}$

Contrario a la conversión de la historia en puesta teatral, en la que el escenario y la disposición de los actores cambia en función del deseo o las intensiones de un hombre, y fiel a los presupuestos y la lógica cientificista que guían su pensamiento, Ingenieros rechaza la ficción de una literatura ilusionista que, pretendidamente científica en un inicio, no supo mantenerse a tono con los preceptos de la ciencia y, precisamente, al ocuparse de la política cayó en manos de las fantasías pergeñadas por la burguesía. Son Elbio, en el fin de la novela, y Sicardi, autor de ese final, encarnado en ese personaje, la expresión de esa retirada de la ciencia ante las exigencias de la política mediocre que, negando la realidad, promete un futuro imposible, una falsa resolución de la cuestión social.

El problema no radica en el encuentro posible entre literatura y ciencia, ni en la denuncia de la inutilidad de la literatura para intervenir en la historia. El problema radica, en cierto sentido, en las formas que adopta la novela al alejarse del naturalismo, en la renuncia al maridaje entre ciencia y literatura. Pero la cuestión de mayor peso se plantea, sin duda, en términos prácticos. Si la reforma social depende de la ciencia, ${ }^{17}$ y ese es, en última instancia, el objetivo, la literatura, con su alto poder de persuasión sobre las masas, debería sumar también sus aportes en esa dirección y, consecuentemente, no desvariar en la ilimitada reproducción de ilusiones sociales, sino, al contrario, contribuir a la comprensión de los múltiples y conflictivos aspectos que supone el progreso.

Así lo planteaba también Enrique Ferri, un autor admirado por Ingenieros, en Los delincuentes en el arte, una obra que se contaba entre lecturas de nuestro autor. Uno de los modelos que tomaba Ferri era también, y precisamente, Zola y en particular La bestia

\footnotetext{
${ }^{16}$ Es interesante reparar en que, al calificar de "falso" el tratamiento de la cuestión social que se hace en la novela, Ingenieros sostiene que su autor es "romántico", introduciendo indirectamente la oposición entre naturalismo y romanticismo.

${ }^{17}$ Cuando decimos "reforma social" somos concientes de la variedad de sentidos en que el concepto puede ser comprendido. Aquí somos ambiguos respetando la ambigüedad del mismo Ingenieros. "Reforma social" es reforma de las condiciones paupérrimas en que vive una importante porción de la población argentina e inmigrante, pero es también reforma de las instituciones a través de las cuales se controla o disciplina esa población.
}

\section{GANPHLAC}

Revista Eletrônica da ANPHLAC, ISSN 1679-1061, No. 17, p. 235-253, jul./dez. 2014.

http://revista.anphlac.org.br/ 
humana. Según Ferri, el antropólogo criminalista podía valerse de las descripciones que ofrecía de algunos personajes criminales la novela de Zola. Se ponía allí en evidencia que el genio artístico había comprendido las novedades de la ciencia, y no sólo eso, sino también que podía divulgarlas. Las obras de Zola, decía Ferri, contribuyen "poderosamente a la evolución de la conciencia común en el público que lee novelas hacia las nuevas verdades de la ciencia" (FERRI, 1899, p. 203). ${ }^{18}$ La literatura, fiel a la ciencia, oficiaba como puente con un público más o menos masivo, contribuyendo a la elaboración de ciertas representaciones que la ciencia misma precisaba difundir como condición de su efectividad social. Si la ciencia pretendía intervenir en la historia necesitaba la ayuda de la literatura.

De aquí el vínculo entre literatura y ciencia y, luego, desde allí, entre literatura e historia. En la novela de Sicardi, la literatura abandonó la ciencia cuando hubo que intervenir en la historia. Al contrario, en el modelo de Ingenieros la mediación de la ciencia hace que ese vínculo no sucumba en la mediocridad, porque, en su discurso, la ciencia es ese el único medio por el cual los hombres pueden y deben intervienen en el curso de la historia. En ese marco, se abandona el protagonismo de la literatura, la centralidad de la ficción, para reconocer en ella sólo un artefacto al servicio de la "política científica".

$* * * *$

Ingenieros escribe este texto en simultaneidad con su renuncia al Partido Socialista, las diferencias que lo alejaban ya desde hacía tiempo del partido son, de alguna manera, las mismas que denuncia tener con Sicardi. Sin embargo, su defensa de la intervención revolucionaria y su oposición a las alianzas políticas convive en él, conflictivamente, con su paulatino acercamiento a los ámbitos de legitimación académica del saber científico que se traducían sin demora en propuestas legislativas y en prácticas concretas para el control social. Así, la figura de Ingenieros en 1902 se retrata justo en la cornisa entre la condena de las desigualdades sociales y la valoración de ciertas intervenciones políticas, a veces

\footnotetext{
${ }^{18}$ Sobre el vínculo entre la literatura y la ciencia criminológica en Argentina puede consultarse el trabajo de Cristina Fernández, "Las historias de vida en José Ingenieros" y el de Hugo Vezzetti, La locura en la Argentina.
}

\section{RANPHLAC}

Revista Eletrônica da ANPHLAC, ISSN 1679-1061, Nº 17, p. 235-253, jul./dez. 2014.

http://revista.anphlac.org.br/ 
asistenciales o preventivas, a veces represivas, a través de las cuales se contenían los efectos sociales negativos del sistema de explotación capitalista. Su crítica a la novela de Sicardi, puede leerse en esa misma bisagra. Por momentos, la crítica golpea contra la peligrosa ingenuidad de un autor que confía en ciertos espíritus con capacidades redentoras y armonizadoras de las diferencias y que rechazan la lucha entre los diversos intereses sociales, pero, por momentos, el reclamo se centra también en la falta de efectividad de una propuesta política que, por renunciar a la ciencia, pierde su control sobre lo real. Dos caras de una misma moneda, la moneda que realza la importancia del conocimiento científico, del conocimiento certero acerca de los intereses y las opciones en juego, como único modo de comprender e intervenir en la historia, en una historia que está necesariamente hecha de necesidades materiales, vitales, que se expresan a veces de los modos más inadecuados para la convivencia.

Así, Sicardi es visto como ese bienintencionado reformador socialista incapaz de reformar; su héroe no posee ni el ardor de un cuerpo que se levanta en repudio del hambre y la injusticia, ni la ciencia que le permitiría avanzar en la transformación controlada de lo social. Ingenieros, en cambio, al menos por esos años, pretende pararse en la vereda opuesta. Como científico, médico y sociólogo, no desconoce la lucha necesaria que implica la realización del capitalismo en estas tierras y la muerte que supone, pero ante ésta se anima al afirmar su necesidad y sólo concibe la posibilidad de llegar a buen término si los hombres que intervienen en política reconocen también esa fatalidad.

\section{GANPHLAC}

Revista Eletrônica da ANPHLAC, ISSN 1679-1061, Nº 17, p. 235-253, jul./dez. 2014.

http://revista.anphlac.org.br/ 


\section{Referencias documentales y bibliográficas}

ANSOLABEHERE, Pablo. El hombre anarquista delincuente, Revista Ibeoramericana, Vol. LXXI, Núm. 211, Abril-Junio, 539-553, 2005.

FERNÁNDEZ, Cristina. Las historias de vida en José Ingenieros, Anclajes, 13: 71-89. 2009. Disponible en: www.scielo.org.ar/pdf/anclajes/v13n1/v13n1a05.pdf. Acceso: 22 En. 2012.

FERRI, Enrique. Los delincuentes en el arte. Madrid: Victoriano Suárez, 1899.

GONZÁLEZ, Horacio. Restos pampeanos. Ciencia, ensayo y política en la cultura argentina del siglo XX, Buenos Aires: Colihue. 1999.

HUERTAS GARCÍA-ALEJO, Rafael. La "novela experimental” y la ciencia positivista, Llull, 7, 29-52. 1984. Disponible en: dialnet.unirioja.es/descarga/articulo/62021.pdf. Acceso: 24 en. 2013.

INGENIEROS, José. Hacia la justicia. In: INGENIEROS, José. Psicopatología en el arte, Obras completas, vol. 3. Buenos Aires: Elmer, 1957.

LUKÁCS, Georg. ¿Narrar o describir? In: SARLO, Beatriz y ALTAMIRANO, Carlos. Literatura y sociedad. Buenos Aires: Centro Editor de América Latina, 1977.

NOUZEILLES, Gabriela. Ficciones somáticas. Naturalismo, nacionalismo y políticas del cuerpo (Argentina 1880-1910). Buenos Aires: Beatriz Viterbo, 2000.

PAFUNDO, Vanesa Mara y Bortz, Javier Elías. De libros extraños a médicos extraños. El caso Sicardi. Revista de historia \& humanidades médicas, 3.1. 2007. Disponible en: http://www.fmv-uba.org.ar/histomedicina_old. Acceso 22 en. 2013.

SALTO, Graciela. Negociaciones literarias de las diferencias de clase y de etnia, Disponible en: http://www.desafio.ufba.br/gt4-016.html. NEHP-CPD-UFBA. s/f. Acceso 21 En. 2013.

SICARDI, Francisco. Hacia la Justicia. In: Libro extraño. Barcelona: El anuario. S/f.

VEZZETTI, Hugo. La locura en la Argentina. Buenos Aires: Paidós, 1985.

\section{GANPHLAC}

Revista Eletrônica da ANPHLAC, ISSN 1679-1061, No. 17, p. 235-253, jul./dez. 2014.

http://revista.anphlac.org.br/ 